\title{
Glioblastoma under Siege: An Overview of Current Therapeutic Strategies
}

\author{
Mayra Paolillo* (D), Cinzia Boselli (i) and Sergio Schinelli \\ Department of Drug Sciences, University of Pavia, Viale Taramelli 12, 27100 Pavia, Italy; \\ cinzia.boselli@unipv.it (C.B.); sergio.schinelli@unipv.it (S.S.) \\ * Correspondence: mayra.paolillo@unipv.it; Tel.: +39-0382-387838
}

Received: 22 November 2017; Accepted: 12 January 2018; Published: 16 January 2018

\begin{abstract}
Glioblastoma is known to be one of the most lethal and untreatable human tumors. Surgery and radiotherapy in combination with classical alkylating agents such as temozolomide offer little hope to escape a poor prognosis. For these reasons, enormous efforts are currently devoted to refine in vivo and in vitro models with the specific goal of finding new molecular aberrant pathways, suitable to be targeted by a variety of therapeutic approaches, including novel pharmaceutical formulations and immunotherapy strategies. In this review, we will first discuss current molecular classification based on genomic and transcriptomic criteria. Also, the state of the art in current clinical practice for glioblastoma therapy in the light of the recent molecular classification, together with ongoing phases II and III clinical trials, will be described. Finally, new pharmaceutical formulations such as nanoparticles and viral vectors, together with new strategies entailing the use of monoclonal antibodies, vaccines and immunotherapy agents, such as checkpoint inhibitors, will also be discussed.
\end{abstract}

Keywords: monoclonal antibodies; alkylating agents; nanoparticles; immunotherapy

\section{Glioblastoma Classification}

Gliomas are the most common primary central nervous system (CNS) tumors and, among these, half of all new diagnosis is represented by glioblastoma (GBM), the most malignant type of brain cancer with a poor prognosis and a median patient survival of approximately 18 months [1]. The histological classification and tumor grading is a critical step for GBM diagnosis and prognosis and the classification according to histological criteria by microscopic observation of specimen has been the main tool for pathologist and clinicians during the last decades.

Recently, the new World Health Organization (WHO) Classification of Tumors of the CNS [2] included both histological and molecular criteria to better integrate information from research and clinic, in order to achieve more accurate diagnosis. Several excellent papers have outlined the relevance and the impact of the most recent glioma classification on diagnosis, prognosis and therapy of this severe brain tumor [3,4]. Molecular subtyping, indeed, appears to be essential to identify subsets of patients that may be uniquely responsive to specific adjuvant therapies [5] and future therapies will be likely designed to target these molecular features.

In addition, as a result of genomic profiling and the Cancer Genome Atlas Project [6], more than 600 genes were sequenced from more than 200 human tumor samples, which revealed the extremely complex genetic profile of GBM and established a set of three main signaling pathways that are commonly altered: the p53 pathway, the receptor tyrosine kinase/Ras/phosphoinositide 3-kinase signaling pathway and the retinoblastoma $(\mathrm{Rb})$ pathway. The consequences of alterations in these pathways are represented by uncontrolled cell proliferation, enhanced cell survival and infiltration skills, contemporarily conferring to the tumor cell the ability to escape from cell-cycle checkpoints and apoptosis [7]. 


\subsection{Molecular Classification of Glioblastoma}

Molecular alterations of gene expression patterns have been assessed between primary and secondary gliomas. Genetic alterations typical for primary GBM are epidermal growth factor receptor (EGFR) gene mutation and amplification, phosphate and tensin homologue (PTEN) mutations and chromosome 10q loss. In secondary GBM, isocitrate dehydrogenase 1 (IDH1) mutations, p53 mutations, and chromosome 19q loss are frequently found [4]. In addition, on the basis of mRNA expression analyses, four GBM subtypes have been identified (classical, pro-neural, neural, and mesenchymal), each with distinctly different patterns of disease progression, survival outcomes and response to therapy $[6,8]$. A subtype of GBM, accounting for nearly $10 \%$ of all glioblastomas, has been found to display isocitrate dehydrogenase 1 or 2 (IDH) mutations; mutant IDH proteins acquire the enzymatic ability to convert $\alpha$-ketoglutarate $(\alpha-K G)$ to d-2-hydroxyglutarate (d-2-HG), eventually leading to aberrant DNA and histone methylation. This subtype mainly includes secondary glioblastomas, therefore sharing this mutation with lower grade astrocytomas, and is typically diagnosed in young adults. The prognosis for these patients, however, is normally more favorable than for IDH-wild-type glioblastoma, with a longer survival $[2,9]$.

\subsection{Epigenetic Analysis: DNA Methylation}

DNA-methylation analysis is a useful tool to distinguish glioblastoma subgroups associated with specific epigenetic and genetic features. On this basis, four subgroups of adult glioblastoma have been identified, including an IDH mutant, and three IDH wild-type glioblastoma subgroups; the IDH mutant subtype has methylated O6-methylguanine methyltransferase (MGMT) promoter, displays a number of chromosomic aberrations and other alterations such as MYC activation, upregulation of the receptor tyrosine kinase (RTK)/Ras/PI3K pathway and mutations of genes encoding inhibitors of the G1/S cell-cycle checkpoint, including the Rb pathway [10,11].

The IDH wild-type glioblastoma subgroups have different DNA-methylation profiles and a fewer copy-number aberations. The so called "receptor tyrosine kinase I" (RTK I) glioblastomas are characterized by platelet-derived growth factor receptor A (PDGFRA) amplification and are mainly diagnosed in young subjects.

The "receptor tyrosine kinase II" (RTK II) and the "mesenchymal" subtypes are generally diagnosed in older patients (from 50 years of age) and the mesenchymal glioblastoma shows a mesenchymal gene-expression profile and is related to radioresistance and shorter survival [10].

Alterations of miRNA levels have been found in almost all cancer biology processes, including cell proliferation, migration, angiogenesis, and chemoresistance. Alterations of GBM miRNAs have been reported and a very recent study identified a panel of miRNAs that are likely to be dysregulated by genomic deletions and amplifications. In addition, the authors found that a miRNA acting as a tumor suppressor, miR-4484, is deleted in GBM, thereby leading to deregulation of a panel of genes involved in various cancer-related processes [12].

In the future, the need to distinguish between neoplastic cells and surrounding cells belonging to tumor niche, in the aim of finding molecular targets for glioma therapy, will represent a real challenge. Recently, two interesting papers have addressed this issue using single-cell analysis coupled to Next-Generation Sequencing (NGS) techniques. In the first study, single cell analysis of cells from the tumor core and surrounding tissue found a wide cellular variation in the tumor genome and transcriptome. Conversely, infiltrating GBM cells appeared to share a consistent gene signature between patients, suggesting the existence of common features underlying the infiltration mechanisms [13].

In another report [14] single cell-RNA-seq profile could distinguish between IDH-mutant astrocytoma and oligodendroglioma on the basis of their distinct tumor microenvironment (TME) and genetic signature. Enhanced proliferation of malignant cells, larger pools of undifferentiated glioma cells and an increase in macrophage over microglia expression programs in TME were related to tumor grade. 


\section{Therapy, State of the Art}

Current standard therapy for GBM includes surgical resection, followed by radiation and co-administration of temozolomide (TMZ), an oral alkylating agent. Extensive surgical resection, though representing the most effective way to increase survival of GBM patients, is hardly feasible depending on tumor localization and infiltration, particularly when highly specialized brain areas are involved, such as those involved in the control of speech, motor function and senses. However, the highly infiltrative behavior of GBM makes surgery nearly ineffective, since tumor cells and glioblastoma stem cells (GSC) colonize the surrounding brain tissue causing relapses located even at distant brain sites [15]. Nevertheless, cutting-edge imaging techniques in both diagnostic and surgical phases make now possible a more aggressive surgical approach with limited side effects for patients [15]. The imaging techniques include functional magnetic resonance imaging (MRI) and diffusion tensor imaging (DTI), during preparatory phase, and ultrasound, computed tomography (CT) and MRI during surgery.

In addition to these techniques, the use of Gamma Knife radiosurgery (GKRS) has provided advantages especially for recurrent glioblastoma (rGBM). GKRS is a type of stereotactic radiosurgery capable of delivering a high dose of radiation to a tumor, sparing healthy surrounding tissue and is particularly used in rGBM. GKRS does not require open resection and allows minimization of radiation-induced necrosis to surrounding brain tissue [16]. The main disadvantage is represented by the fact that tumor areas not well detected by MRI cannot be reached by GKRS. In addition, radionecrosis and especially radiation-induced edema are strong drawbacks that have been reported in a high percentage of patients, nearly $30 \%$, who received high radiation doses [17]. Interestingly, the concomitant administration of bevacizumab prolonged patient survival and significantly reduced detectable adverse radiation effects [18].

Hyperthermia is another strategy adopted in the treatment of GBM patients. Hyperthermia brings tumor tissue temperature to a range of $41-46^{\circ} \mathrm{C}$, thereby inducing physiological changes in tumor cells, such as protein misfolding, aggregation, alteration of signal transduction pathways, eventually leading to apoptosis [19]. The efficiency of hyperthermia treatment significantly depends on the temperature at the targeted tumor site, the period of exposure, and the features of cancer cells. Hyperthermia is generally achieved by the use of microwaves, infrared irradiation, ultrasound and tubes containing boiling water. Conversely, these systems suffer from limitations including unintended heating of healthy tissue with spread of heat by the blood, especially in highly vascularized tumors, and low diffusion of heat to the target sites [19]. Magnetic materials can be used to induce hyperthermia (magnetic hyperthermia, MHT) [20], but some undesirable side effects still remain. The use of nanoparticles (Nps) in combination with hyperthermia is a novel approach that allows controlled heating of targeted tumor tissue [20].

However, despite these technologies, differentiating between normal brain and tumor tissue continues to be a major challenge and, even with advances in surgical resection, the prognosis for GBM patients remains poor.

On the pharmacological therapy side, great efforts have been made to develop new pharmacological tools leading to a series of clinical trials recently completed or currently ongoing (Tables 1 and 2).

The classical clinical practice includes TMZ treatment for GBM patients. TMZ is a derivative of the alkylating agent dacarbazine and is active against human cancers such as melanomas and astrocytomas by inducing cell cycle arrest at G2/M phase and eventually leading to apoptosis [21-23]. Particularly, TMZ acts by methylating adenine and guanine residues to form N3-methyladenine, N7-methylguanine and O6-methylguanine. The methylated bases can be repaired by DNA repair enzyme systems that reverse guanine methylation induced by $\mathrm{TMZ}$, thus preventing apoptosis initiation. The mechanisms of resistance to TMZ depend on different DNA repair systems, among which methylguanine methyltransferase (MGMT) aroused great interest [24,25]. MGMT is an enzyme involved in DNA repair processes that counteract mutagenesis from alkylating agents [24,25]. High levels of MGMT 
activity in cancer cells lead to a phenotype that is resistant to alkylating agents and MGMT is likely to play an important role in therapeutic failure. Indeed, epigenetic silencing of the MGMT gene by promoter methylation is associated with loss of MGMT expression [26] and diminished DNA-repair activity. Promoter methylation has also been associated with longer overall survival in patients with glioblastoma treated with carmustine or TMZ [26].

To overcome this resistance mechanism, the combination of capecitabine and TMZ was designed. Capecitabine is a prodrug of the pyrimidine analog 5-FU (5-fluorouracil), which is enzymatically converted to 5-FU and leads to inhibition of MGMT repair activity, probably through depletion of MGMT protein and mRNA [27-30]. Clinical trials including the association capecitabine/TMZ are still ongoing (Table 2).

Table 1. Major studies completed during the last three years (2015-2017).

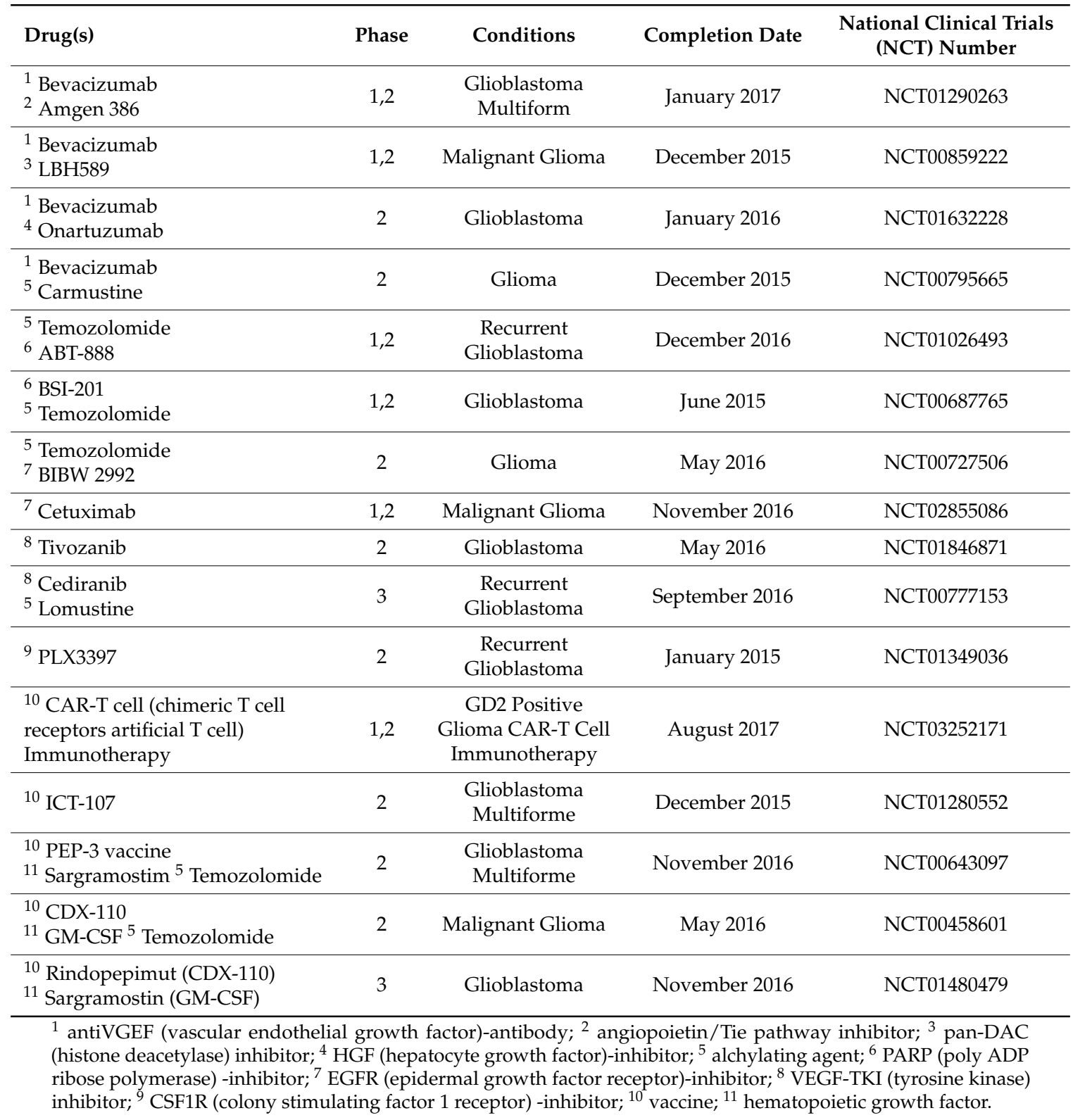


Table 2. Major ongoing clinical trials based on pharmacological treatment(s) of malignant glioma.

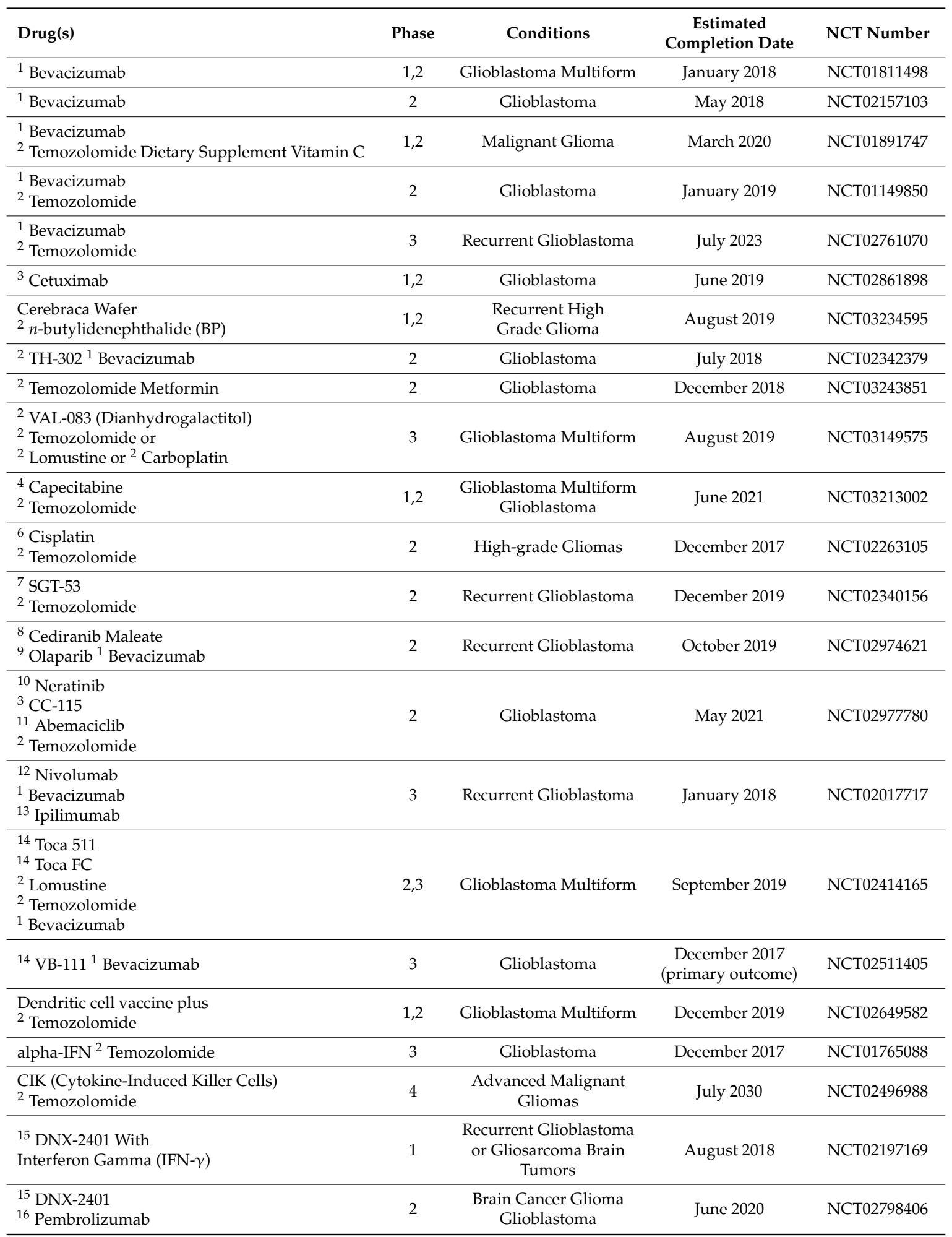

${ }^{1}$ VGEF-inhibitor; ${ }^{2}$ alchilating agent; ${ }^{3}$ EGFR-inhibitor; ${ }^{4}$ Thymidylate synthase inhibitor; ${ }^{5}$ mTOR (mammalian target of rapamycin)-inhibitor; ${ }^{6}$ DNA-binding inhibitor; ${ }^{7}$ liposome encapsulating the wtp53 DNA sequence; ${ }^{8}$ VEGFR inhibitor; ${ }^{9}$ PARP inhibitor; ${ }^{10}$ tyrosine kinase inhibitor; ${ }^{11}$ Dual Inhibitor of CDK4 (cycline dependent kinase) and CDK6; ${ }^{12}$ anti PD-1R (programmed death receptor) antibody; ${ }^{13}$ anti CTLA4 (cytotoxic T-lymphocyte antigen 4)-antibody; ${ }^{4}$ oncolytic virotherapy; ${ }^{15}$ oncolytic adenovirus; ${ }^{16}$ anti PD-1. 


\section{New Strategies}

\subsection{Nanoparticles}

Nanoparticles (Nps) are structures in the nanometer size range having different structures and properties and, in general, are widely studied for biomedical applications [31]. In GBM treatment several nanoparticle types are under investigation with different application strategies.

Lipid carriers are bilayered vesicles composed of phospholipid membranes (liposomes). Liposome phospholipids are mainly represented by biocompatible fatty acids, such as phosphatidylcholine and ethanolamine, and display on their surface both hydrophilic and hydrophobic regions [31]. These vesicles are very flexible tools, can be loaded by a variety of drugs and are highly biocompatible. Paclitaxel is a classical and effective chemotherapeutic drug that is unable to cross the brain barrier (BBB) and for this reason cannot be used for brain tumor treatment. In the aim to make paclitaxel cross the BBB, liposomes have been loaded with the drug and used for GBM therapy [32]. Also other drugs such as peptides, monoclonal antibodies, siRNA and other molecules, which otherwise would not be able to pass the BBB, are under investigation for use in brain tumor treatment as liposome formulations.

Inorganic Nps can be utilized for diagnostic and therapeutic purposes. Magnetic Nps (MNps) are the most common Nps used in biomedical applications due to their high biocompatibility; injectable super paramagnetic iron oxide Nps (SPION) can be also used in MRI with lower toxicity effects and higher sensitivity compared to conventional contrast agents [33]. In addition, SPIONs display interesting features such as high intratumoral penetration and controlled heating: hyperthermia, in fact, besides destroying tumor cells, can also be used to deliver drugs to tumors such as GBM. Similarly, gold Nps can be used both as contrast agent for MRI and for photothermal therapy. Particularly, gold nanorods (GNRs) have been used for thermal ablation of GBM cells, in vivo [20].

An interesting application is the use of Nps in combination with siRNAs; it is known that stimulation of the thyrosin kinase receptor c-Met induces proliferation of glioma cells and resistance to chemotherapy; intravenous administration of polyethylene glicol (PEG) Nps loaded with c-Met siRNA reduced c-Met expression and powerfully inhibited cell proliferation and resistance to chemotherapeutic agents in GBM cells [34].

Glioblastoma stem cells (GSCs) are currently held responsible for GBM infiltration in the brain tissue, proliferation and resistance to chemotherapy [35]. For these reasons, they appear as a target of primary importance in the fight against GBM; in GBM patients the micro RNA miR-1 has been found to be deregulated and delivery of miR-1 by Nps has been found to efficiently target GSC thereby reducing cell migration and proliferation [36].

\subsection{Targeted Therapies and Immunotherapy}

It was once thought that the central nervous system was devoid of normal immunologic function and lymphatic vessels [37]. Indeed, some CNS features support this theory, such as the blood-brain barrier structure, which allows for selective entry of immune cells from the peripheral blood into the brain tissue, and the low number of circulating T cells in the CNS. Concerning the lack of lymphatic vessels within the CNS, in 2015 an important finding changed this perspective: meningeal lymphatic vessels were identified in mouse brain and these vessels were found to be a path for cerebrospinal fluid drainage, demonstrating for the first time the presence of a functional lymphatic system in the central nervous system [38].

Furthermore, under physiologic conditions, the brain hosts several populations of immune cells such as microglia, which stem from hematopoietic cells and colonize CNS during embryonic development. Microglial cells migrate to inflammatory sites in the CNS, activate and behave like phagocytes or antigen presenting cells, secreting cytokines and chemokines [37].

This picture is different in GBM patients, who display a slight but detectable immune suppression condition, compared to the general population, and low adaptive immune responses. In addition, the tumor microenvironment is rich in immunosuppressive factors secreted by the tumor, like 
transforming growth factor beta (TGF- $\beta$ ) and vascular endothelial growth factor (VEGF) that suppresses cytotoxic $\mathrm{T}$ cell activity [39].

In this background, different approaches are under investigation: in targeted therapies, immune cells or antibodies directed against tumor antigens are given to patients and this approach does not require activation of patients' immune system. Over recent years several molecular targets have been identified and tested in GBM therapy, with controversial results (Table 1).

In GBM the so-called EGFRvIII mutation is frequently found; this mutation arises from a deletion of 267 amino acids of the extracellular domain leading to the expression of mutants with a unique extracellular domain [40]. This mutant EGFRvIII is ligand independent, constitutively active and, because of its important mitogenic effects, is related to a short survival.

Some monoclonal antibodies (mAbs) binding to EGFRvIII have been developed but, despite the relevant results of antibody-based therapy in the treatment of other cancer types such as renal carcinoma, breast cancer, melanoma, and hematologic cancers, these results have not been equally successful in GBM [41]. Among the antibodies developed to target wtEGFR and EGFRvIII, cetuximab, panitumumab, and nimotuzumab, which bind the extracellular EGFR domain, were included in clinical trials that were recently completed with varying results (Table 1). In a phase II study patients were stratified on the basis of EGFR gene amplification status and were administered cetuximab intravenously [42]. Cetuximab had little effect and the median overall survival was 5 months, showing no significant correlation between EGFR status and response or overall survival [36]. Other clinical trials involving similar antibody-based therapies have been equally unsuccessful, even when nimotuzumab was administered with concurrent radiotherapy [40].

Indeed, the first $\mathrm{mAb}$ tried in the therapy of GBM patients was bevacizumab. Bevacizumab is a humanized monoclonal antibody that binds to the different forms of the vascular endothelial growth factor (VEGF). Bevacizumab is currently used in the therapy of a variety of tumor types and is also in trial for GBM therapy. However, in recent, randomized, double-blind, placebo-controlled studies designed to evaluate first-line use of bevacizumab together with the standard therapy, chemoradiation and TMZ, no increase of median overall survival was reported. It should be also noted that patients were stratified by MGMT promoter methylation and other gene mutations but no group showed benefits from bevacizumab treatment [43] with, in contrast, a marked increase of adverse events typically related to bevacizumab, such as deep vein thrombosis, gastrointestinal perforations, and hemorrhage [43].

New insights could still come from ongoing clinical trials but at the moment classical antibody-based approaches are making time.

A promising possibility is represented by the use of mAbs linked to cytotoxic molecules that specifically target cancer cells, thereby delivering drugs or toxins; these mAbs are named antibody drug-conjugate (ADC) and are under investigation for the use in GBM patients [44]. Immunotoxins such as Pseudomonas aeruginosa exotoxin A (PE) and diphtheria toxin (DT) have been tested as ADC in GBM patients but the clinical trials did not produce the expected results. Other strategies include anti-EGFR mAbs conjugated with drugs not suitable to use in therapy due to their high toxicity, such as maytansine and monomethyl auristatin F (MMAF), both inhibitors of microtubules assembly. Clinical trials, including the use of these ADCs alone or in combination with temozolomide, are in phases I and II, and preliminary results indicate a good and selective uptake of these conjugates by tumor cells and a tolerable toxicity profile, limited to retinal toxicity [44].

Another interesting target is the $\alpha \mathrm{v} \beta 3$ integrin receptor, which is highly expressed in glioblastoma and can be targeted by mAbs or by integrin receptor ligands conjugated to cytotoxic drugs; preclinical studies are giving promising results [45].

Immunotherapy offers a different approach from chemotherapy, targeted therapy, radiation and surgery, raising new hopes, particularly for immune checkpoints inhibitors. T lymphocytes can recognize antigens expressed by cancer cells but, conversely, immune checkpoints, particularly programmed cell death (PD)-1 receptor and its ligand (PD-L1), can suppress the activity of $\mathrm{T}$ 
lymphocytes by inducing apoptosis in activated immune cells [46,47]. The expression of PD-L1 has been demonstrated in glioma cell lines and tumor tissues. Quite interestingly, it was reported that PD-L1 expression was significantly greater at the edges of the tumors than in the tumor cores, thereby leading to the formation of a sort of barrier between the tumor cells and cytotoxic $\mathrm{T}$ cells that has been defined as "molecular shield". The strategy of blocking PD-1 and PD-L1 by mAbs has given encouraging results in the treatment of other cancer types; pembrolizumab and nivolumab, targeting PD-1, were approved by Food and Drug Administation (FDA) and European Medicines Agency (EMA) for advanced melanoma therapy in late 2014 and for non-small cell lung cancer (NSCLC) therapy in March 2015 [48,49].

The growing interest in immune checkpoint inhibitors and the encouraging results in the treatment of these cancer types have driven in recent years the attention of researchers towards the use of anti PD-1 and PD-L1 mAb in GBM therapy. Preclinical studies in mice have given promising results and a number of clinical studies involving pembrolizumab and nivolumab alone or in combination with other agents (bevacizumab, temozolomide) are starting or still ongoing and results will be available in a few years.

Also the very new therapies involving the use of genetically modified T cells expressing chimeric antigen receptors (CARs) may represent a new offensive strategy in the GBM siege. These T cells are modified to specifically recognize GBM antigens such as IL13R $\alpha 2$, HER2, EphA2, and EGFRvIII, the first antigens to be tried in this type of immunotherapy [50,51], and phase I trials in humans are ongoing. In one reported case, autologous CAR T cells targeting IL13R $\alpha 2$ induced a complete response in a patient with recurrent multifocal glioblastoma, with dramatic improvements in quality of life and a return to normal life activities, allowing 7,5 disease free months survival [52].

\subsection{Oncolytic Viruses}

Oncolytic viruses (OV) specifically target cancer cells; OV have been designed to take advantage of tumor-specific mutations, or signaling pathways that are constitutively activated in tumors, and are selected to enter tumor cells overexpressing tumor antigens [53]. The infected tumor cells thereby undergo apoptotic processes or necrosis and eventually cell death.

Several OV are under investigation for high-grade glioma therapy and, among these, two types of modified Herpes simplex virus 1 (HSV1) and adenovirus (AdV) are in clinical trial. Indeed, a variety of oncolytic HSV mutants such as R3616, HSV-1716, hrR3, G207, and G47 $\Delta$ have been designed for targeting glioblastoma. All these mutants display deleted or mutated viral genes, thus reducing neurotoxicity while not affecting infection of dividing cells, particularly those with activated Ras pathway signaling [54]. In G207 mutant the ICP6 gene encoding the viral ribonucleotide reductase is inactivated in order to increase safety, since this enzymatic function is recovered in proliferating glioma cells but not in non-tumor quiescent cells [55]. In addition, G207 has been found to interfere with replication of p16 tumor suppressor gene defective cells [56], such as glioma cells, and is now in phase II trial for rGBM therapy.

$\mathrm{AdV}$ is a non-enveloped virus with a double-stranded, linear DNA genome. There are multiple engineered versions under investigation, including DNX-2401 and ADV-TK that are in clinical trial. DNX-2401 mutation allows for replication only in cells bearing $\mathrm{Rb}$ tumor suppressor deletion [55]. The tumor specificity is given by the presence of the cyclic arginine/glycine/aspartic acid (RGD) peptide into the viral capsid region responsible for attachment to host cells; the RGD peptide directs the virus towards RGD-binding integrins, which are highly expressed in gliomas. Preliminary recently published results from trials show that therapy with DNX-2401 in combination with temozolomide or interferon- $\gamma$ is well tolerated and shows significant therapeutic activity $[57,58]$.

ADV-TK is an adenoviral vector engineered to express the Herpes thymidine kinase gene followed by administration of an anti-herpetic prodrug (ganciclovir-GCV). A randomized phase II clinical trial demonstrated progression-free survival and overall survival benefit associated with ADV-TK gene therapy, which was also shown to be safe [59]. 
Another interesting therapeutic strategy in clinical trial is represented by the use of Toca 511 and Toca FC [60]. These agents act in combination and, considering the rationale of this therapy, are expected to display very limited toxic effects. Toca 511 (vocimagene amiretrorepvec) is an injectable retroviral replicating vector encoding an enzyme, cytosine deaminase (CD), derived from yeast and not expressed by humans. $C D$ is a prodrug activator that is selectively delivered to cancer cells that, in turn, acquire the ability to synthesize CD protein. This enzyme acts on a substrate, 5 -fluorocytosine (5-FC), a prodrug that is inactive in human but is converted in 5-FU, a widely used anti-cancer agent, by the CD protein. Toca FC is an oral formulation of 5-fluorocytosine (5-FC) that is easily absorbed, is able to cross the blood-brain barrier and to diffuse into the cancer cells [60]. Toca 511 and Toca FC are currently in trial in patients with recurrent high-grade glioma (Table 2) and are under investigation in a pivotal Phase 3 trial.

\subsection{Vaccines}

The EGFRvIII mutation occurs in roughly $20-30 \%$ of all glioblastomas and its potential immunogenicity has raised substantial interest in the neuro-oncology field; the studies aimed at finding new targets for glioblastoma therapy resulted in the development of rindopepimut, a peptide vaccine containing the amino acid sequence found in the EGFRvIII deletion mutation conjugated to keyhole limpet hemocyanin. In four separate glioblastoma trials, ACTIVATE, ACT II, ACT III, [61] rindopepimut given in combination with temozolomide was well tolerated and a consistent progression-free survival, in the range of 15 months from diagnosis, and overall survival of 24 months from diagnosis was found, which compared favorably with patient cohorts who received standard treatment. In the Phase II ReACT trial for recurrent glioblastoma, rindopepimut was given in combination with bevacizumab and a small number of patients with bulk disease appeared to benefit from vaccine therapy, when combined with bevacizumab [62,63]. Afterwards, the ACT IV was designed as a randomized, placebo-controlled, phase III clinical trial to assess whether the co-administration of rindopepimut and standard temozolomide therapy increased overall survival compared with temozolomide alone in patients with newly diagnosed EGFRvIII-expressing glioblastoma. In spite of previous promising results, final data analysis of this study demonstrated no survival benefit for patients with EGFRvIII-positive glioblastoma who received rindopepimut with temozolomide versus those who received a control, with median overall survival of 20.4 months compared with 21.1 months for the control arm [64].

Other glioblastoma vaccines are under investigation in single-arm and randomized Phase II trials and results will be available in a short time.

\section{Conclusions}

Evidence coming from preclinical studies and clinical trials indicate that strategies to counteract GBM aggressiveness are multiplying and that knowledge of GBM mutations and genetic profiling can highlight possible molecular targets for therapies. It is also clear that traditional therapies such as surgery, chemotherapy and radiation still remain the first line approaches to GBM and hopes to improve life quality and overall life expectancy of GBM patients mainly lie, at the moment, in the new immunotherapy strategies. In the coming years a number of clinical trials will give fundamental insights about these therapeutic approaches and, contemporarily, basic research must pursue the objective of discovering new mechanisms and new targets to help and direct clinical research.

Acknowledgments: This work was supported by a PRIN (Project of Relevant National Interest) grant from MIUR, Italian Ministry for University and Research.

Author Contributions: Mayra Paolillo contributed to the "New Strategies" section; Cinzia Boselli contributed to the "Therapy, State of the Art" section and to the clinical trials overview; Sergio Schinelli contributed to the "Glioblastoma Classification" section.

Conflicts of Interest: The authors declare no conflict of interest. 


\section{References}

1. Di Carlo, D.T.; Cagnazzo, F.; Benedetto, N.; Morganti, R.; Perrini, P. Multiple high-grade gliomas: Epidemiology, management, and outcome. A systematic review and meta-analysis. Neurosurg. Rev. 2017, 1-13. [CrossRef] [PubMed]

2. Louis, D.N.; Ohgaki, H.; Wiestler, O.D.; Cavenee, W.K. WHO Classification of Tumours of the Central Nervous System, Revised 4th ed.; International Agency for Research on Cancer (IARC): Lyon, France, 2016; pp. 10-122.

3. Verhaak, R.G.W.; Hoadley, K.A.; Purdom, E.; Wang, V.; Qi, Y.; Wilkerson, M.D.; Miller, C.R.; Ding, L.; Golub, T.; Mesirov, J.P.; et al. Integrated genomic analysis identifies clinically relevant subtypes of glioblastoma characterized by abnormalities in PDGFRA, IDH1, EGFR, and NF1. Cancer Cell 2010, 17, 98-110. [CrossRef] [PubMed]

4. Reifenberger, G.; Wirsching, H.G.; Knobbe-Thomsen, C.B.; Weller, M. Advances in the molecular genetics of gliomas-Implications for classification and therapy. Nat. Rev. Clin. Oncol. 2017, 14, 434-452. [CrossRef] [PubMed]

5. Vitucci, M.; Hayes, D.N.; Miller, C.R. Gene expression profiling of gliomas: Merging genomic and histopathological classification for personalised therapy. Br. J. Cancer 2011, 104, 545-553. [CrossRef] [PubMed]

6. Parsons, D.W.; Jones, S.; Zhang, X.; Lin, J.C.; Leary, R.J.; Angenendt, P.; Kinzler, K.W. An integrated genomic analysis of human glioblastoma multiforme. Science 2008, 321, 1807-1812. [CrossRef] [PubMed]

7. Chen, J.; McKay, R.M.; Parada, L.F. Malignant glioma: Lessons from genomics, mouse models, and stem cells. Cell 2012, 149, 36-47. [CrossRef] [PubMed]

8. Bhat, K.P.L.; Balasubramaniyan, V.; Vaillant, B.; Ezhilarasan, R.; Hummelink, K.; Hollingsworth, F.; Wani, K.; Heathcock, L.; James, J.D.; Goodman, L.D.; et al. Mesenchymal differentiation mediated by NF-kB promotes radiation resistance in glioblastoma. Cancer Cell 2013, 24, 331-346. [CrossRef] [PubMed]

9. Ceccarelli, M.; Barthel, F.P.; Malta, T.M.; Sabedot, T.S.; Salama, S.R.; Murray, B.A.; Morozova, O.; Newton, Y.; Radenbaugh, A.; Pagnotta, S.M.; et al. Molecular profiling reveals biologically discrete subsets and pathways of progression in diffuse glioma. Cell 2016, 164, 550-563. [CrossRef] [PubMed]

10. Sturm, D.; Witt, H.; Hovestadt, V.; Khuong-Quang, D.-A.; Jones, D.T.W.; Konermann, C.; Pfaff, E.; Tönjes, M.; Sill, M.; Bender, S.; et al. Hotspot mutations in H3F3A and IDH1 define distinct epigenetic and biological subgroups of glioblastoma. Cancer Cell 2012, 22, 425-437. [CrossRef] [PubMed]

11. Brennan, C.W.; Verhaak, R.G.; McKenna, A.; Campos, B.; Noushmehr, H.; Salama, S.R.; Zheng, S.; Chakravarty, D.; Sanborn, J.Z.; Benman, S.H.; et al. The somatic genomic landscape of glioblastoma. Cell 2013, 155, 462-477. [CrossRef] [PubMed]

12. Nawaz, Z.; Patil, V.; Thinagararjan, S.; Rao, S.A.; Hegde, A.S.; Arivazhagan, A.; Santosh, V.; Somasundaram, K. Impact of somatic copy number alterations on the glioblastoma miRNome: miR-4484 is a genomically deleted tumour suppressor. Mol. Oncol. 2017, 11, 927-944. [CrossRef] [PubMed]

13. Darmanis, S.; Sloan, S.A.; Croote, D.; Mignardi, M.; Chernikova, S.; Samghababi, P.; Zhang, Y.; Neff, N.; Kowarsky, M.; Caneda, C.; et al. Single-Cell RNA-Seq Analysis of Infiltrating Neoplastic Cells at the Migrating Front of Human Glioblastoma. Cell Rep. 2017, 21, 1399-1410. [CrossRef] [PubMed]

14. Venteicher, A.S.; Tirosh, I.; Hebert, C.; Yizhak, K.; Neftel, C.; Filbin, M.G.; Hovestadt, V.; Escalante, L.E.; Shaw, M.L.; Rodman, C.; et al. Decoupling genetics, lineages, and microenvironment in IDH-mutant gliomas by single-cell RNA-seq. Science 2017, 355, eaai8478. [CrossRef] [PubMed]

15. Davis, M.E. Glioblastoma: Overview of Disease and Treatment. Clin. J. Oncol. Nurs. 2016, 20, S2-S8. [CrossRef] [PubMed]

16. Larson, E.W.; Peterson, H.E.; Lamoreaux, W.T.; MacKay, A.R.; Fairbanks, R.K.; Call, J.A.; Carlson, J.D.; Ling, B.C.; Demakas, J.J.; Cooke, B.S.; et al. Clinical outcomes following salvage Gamma Knife radiosurgery for recurrent glioblastoma. World J. Clin. Oncol. 2014, 5, 142-148. [CrossRef] [PubMed]

17. Koga, T.; Maruyama, K.; Tanaka, M.; Ino, Y.; Saito, N.; Nakagawa, K.; Shibahara, J.; Todo, T. Extended field stereotactic radiosurgery for recurrent glioblastoma. Cancer 2011, 118, 4193-4200. [CrossRef] [PubMed]

18. Park, K.-J.; Kano, H.; Iyer, A.; Liu, X.; Niranjan, A.; Flickinger, J.C.; Lieberman, F.S.; Lunsford, L.D.; Kondziolka, D. Salvage gamma knife stereotactic radiosurgery followed by bevacizumab for recurrent glioblastoma multiforme: A case-control study. J. Neurooncol. 2011, 107, 323-333. [CrossRef] [PubMed] 
19. Hildebrandt, B.; Wust, P.; Ahlers, O.; Dieing, A.; Sreenivasa, G.; Kerner, T.; Felix, R.; Riess, H. The cellular and molecular basis of hyperthermia. Crit. Rev. Oncol. Hematol. 2002, 43, 33-56. [CrossRef]

20. Pourgholi, F.; hajivalili, M.; Farhad, J.-N.; Kafil, H.S.; Yousefi, M. Nanoparticles: Novel vehicles in treatment of glioblastoma. Biomed. Pharmacother. 2016, 77, 98-107. [CrossRef] [PubMed]

21. Sang, Y.L. Temozolomide resistance in glioblastoma multiforme. Genes Dis. 2016, 3, 198-210. [CrossRef]

22. Kawaguchi, K.; Igarashi, K.; Li, S.; Han, Q.; Tan, Y.; Kiyuna, T.; Miyake, K.; Murakami, T.; Chmielowski, B.; Nelson, S.D.; et al. Combination treatment with recombinant methioninase enables temozolomide to arrest a BRAF V600E melanoma in a patient-derived orthotopic xenograft (PDOX) mouse model. Oncotarget 2017, 8 , 85516-85525. [CrossRef] [PubMed]

23. Van den Bent, M.J.; Smits, M.; Kros, J.M.; Chang, S.M. Diffuse Infiltrating Oligodendroglioma and Astrocytoma. J. Clin. Oncol. 2017, 35, 2394-2401. [CrossRef] [PubMed]

24. Shi, J.; Dong, B.; Zhou, P.; Guan, W.; Peng, Y. Functional network analysis of gene-phenotype connectivity associated with temozolomide. Oncotarget 2017, 8, 87554-87567. [CrossRef] [PubMed]

25. Roos, W.P.; Batista, L.F.Z.; Naumann, S.C.; Wick, W.; Weller, M.; Menck, C.F.M.; Kaina, B. Apoptosis in malignant glioma cells triggered by the temozolomide-induced DNA lesion O6-methylguanine. Oncogene 2006, 26, 186-197. [CrossRef] [PubMed]

26. Hegi, M.E.; Diserens, A.C.; Gorlia, T.; Hamou, M.F.; de Tribolet, N.; Weller, M.; Kros, J.M.; Hainfellner, J.A.; Mason, W.; Mariani, L.; et al. MGMT gene silencing and benefit from temozolomide in glioblastoma. N. Engl. J. Med. 2005, 352, 997-1003. [CrossRef] [PubMed]

27. Fine, R.L.; Fogelman, D.R.; Schreibman, S.M. Effective treatment of neuroendocrine tumors with temozolomide and capecitabine. J. Clin. Oncol. 2005, 23, 4216. [CrossRef]

28. Kotteas, E.A.; Syrigos, K.N.; Saif, M.W. Profile of capecitabine/temozolomide combination in the treatment of well-differentiated neuroendocrine tumors. Oncol. Targets Ther. 2016, 9, 699-704. [CrossRef]

29. Owen, D.H.; Alexander, A.J.; Konda, B.; Wei, L.; Hemminger, J.A.; Schmidt, C.R.; Abdel-Misih, S.R.Z.; Dillhoff, M.E.; Sipos, J.A.; Kirschner, L.S.; et al. Combination therapy with capecitabine and temozolomide in patients with low and high grade neuroendocrine tumors, with an exploratory analysis of O6-methylguanine DNA methyltransferase as a biomarker for response. Oncotarget 2017, 8, 104046-104056. [CrossRef] [PubMed]

30. Murakami, J.; Lee, Y.-J.; Kokeguchi, S.; Tsujigiwa, H.; Asaumi, J.-I.; Nagatsuka, H.; Fukui, K.; Kuroda, M.; Tanaka, N.; Matsubara, N. Depletion of O6-methylguanine-DNA methyltransferase by O6-benzylguanine enhances 5-FU cytotoxicity in colon and oral cancer cell lines. Oncol. Rep. 2007, 17, 1461-1467. [CrossRef] [PubMed]

31. Kaur, I.P.; Bhandari, R.; Bhandari, S.; Kakkar, V. Potential of solid lipid nanoparticles in brain targeting. J. Control. Release 2008, 127, 97-109. [CrossRef] [PubMed]

32. Belhadj, Z.; Zhan, C.; Ying, M.; Wei, X.; Xie, C.; Yan, Z.; Lu, W. Multifunctional targeted liposomal drug delivery for efficient glioblastoma treatment. Oncotarget 2017, 8, 66889-66900. [CrossRef] [PubMed]

33. Zhang, F.; Huang, X.; Zhu, L.; Guo, N.; Niu, G.; Swierczewska, M.; Lee, S.; Xu, H.; Wang, A.Y.; Mohamedali, K.A.; et al. Noninvasive monitoring of orthotopic glioblastoma therapy response using RGD-conjugated iron oxide nanoparticles. Biomaterials 2012, 33, 5414-5422. [CrossRef] [PubMed]

34. Jin, J.; Bae, K.H.; Yang, H.; Lee, S.J.; Kim, H.; Kim, Y.; Joo, K.M.; Seo, S.W.; Park, T.G.; Nam, D.-H. In vivo specific delivery of c-met siRNA to glioblastoma using cationic solid lipid nanoparticles. Bioconjug. Chem. 2011, 22, 2568-2572. [CrossRef] [PubMed]

35. Paolillo, M.; Schinelli, S. Integrins and Exosomes, a Dangerous Liaison in Cancer Progression. Cancers 2017, 9, 95. [CrossRef] [PubMed]

36. Wang, X.; Huang, X.; Yang, Z.; Gallego-Perez, D.; Ma, J.; Zhao, X.; Xie, J.; Nakano, I.; Lee, L.J. Targeted delivery of tumor suppressor microRNA-1 by transferrin-conjugated lipopolyplex nanoparticles to patient-derived glioblastoma stem cells. Curr. Pharm. Biotechnol. 2014, 15, 839-846. [CrossRef] [PubMed]

37. Sehgal, A.; Berger, M.S. Basic concepts of immunology and neuroimmunology. Neurosurg. Focus 2000, 9, 1-6. [CrossRef]

38. Louveau, A.; Smirnov, I.; Keyes, T.J.; Eccles, J.D.; Rouhani, S.J.; Peske, J.D.; Derecki, N.C.; Castle, D.; Mandell, J.W.; Lee, K.S.; et al. Structural and functional features of central nervous system lymphatic vessels. Nature 2015, 523, 337-341. [CrossRef] [PubMed]

39. McGranahan, T.; Li, G.; Nagpal, S. History and current state of immunotherapy in glioma and brain metastasis. Ther. Adv. Med. Oncol. 2017, 9, 347-368. [CrossRef] [PubMed] 
40. Padfield, E.; Ellis, H.P.; Kurian, K.M. Current therapeutic advances targeting EGFR and EGFRvIII in Glioblastoma. Front. Oncol. 2015, 5, 5. [CrossRef] [PubMed]

41. Thomas, A.A.; Ernstoff, M.S.; Fadul, C.E. Immunotherapy for the Treatment of Glioblastoma. Cancer J. 2012, 18, 59-68. [CrossRef] [PubMed]

42. Neyns, B.; Sadones, J.; Joosens, E.; Bouttens, F.; Verbeke, L.; Baurain, J.-F.; D’Hondt, L.; Strauven, T.; Chaskis, C.; Michotte, P.I.A.; et al. Stratified phase II trial of cetuximab in patients with recurrent high-grade glioma. Ann. Oncol. 2009, 20, 1596-1603. [CrossRef] [PubMed]

43. Hernández-Pedro, N.Y.; Rangel-López, E.; Vargas Félix, G.; Pineda, B.; Sotelo, J. An update in the use of antibodies to treat glioblastoma multiforme. Autoimmune Dis. 2013, 2013, 1-14. [CrossRef] [PubMed]

44. Gan, H.K.; van den Bent, M.; Lassman, A.B.; Reardon, D.A.; Scott, A.M. Antibody-drug conjugates in glioblastoma therapy: The right drugs to the right cells. Nat. Rev. Clin. Oncol. 2017, 14, 695-707. [CrossRef] [PubMed]

45. Paolillo, M.; Serra, M.; Schinelli, S. Integrins in glioblastoma: Still an attractive target? Pharmacol. Res. 2016, 113, 55-61. [CrossRef] [PubMed]

46. Xue, S.; Hu, M.; Li, P.; Ma, J.; Xie, L.; Teng, F.; Zhu, Y.; Fan, B.; Mu, D.; Yu, J. Relationship between expression of PD-L1 and tumor angiogenesis, proliferation, and invasion in glioma. Oncotarget 2017, 8, 49702-49712. [CrossRef] [PubMed]

47. Xue, S.; Hu, M.; Iyer, V.; Yu, J. Blocking the PD-1/PD-L1 pathway in glioma: A potential new treatment strategy. J. Hematol. Oncol. 2017, 10, 81. [CrossRef] [PubMed]

48. Hamid, O.; Robert, C.; Daud, A.; Hodi, F.S.; Hwu, W.J.; Kefford, R.; Wolchok, J.D.; Hersey, P.; Joseph, R.W.; Weber, J.S. Safety and tumor responses with lambrolizumab (anti-PD-1) in melanoma. N. Engl. J. Med. 2013, 369, 134-144. [CrossRef] [PubMed]

49. Rizvi, N.A.; Shepherd, F.A.; Antonia, S.J.; Brahmer, J.R.; Chow, L.Q.; Goldman, J.; Juergens, R.; Borghaei, H.; Ready, N.E.; Gerber, D.E.; et al. First-line monotherapy with nivolumab (anti-PD-1; BMS-936558, ONO-4538) in advanced non-small cell lung cancer (NSCLC): Safety, efficacy, and correlation of outcomes with PD-11 status. Int. J. Radiat. Oncol. 2014, 90, S31. [CrossRef]

50. Brown, C.E.; Aguilar, B.; Starr, R.; Yang, X.; Chang, W.C.; Weng, L.; Chang, B.; Sarkissian, A.; Brito, A.; Sanchez, J.F.; et al. Optimization of IL13R $\alpha 2$-Targeted Chimeric Antigen Receptor T Cells for Improved Anti-tumor Efficacy against Glioblastoma. Mol. Ther. 2017, 16, 31-44. [CrossRef] [PubMed]

51. Sarah, C. Immunotherapy: CAR T cells in glioblastoma. Nat. Rev. Drug Discov. 2017, 16, 602. [CrossRef] [PubMed]

52. Brown, C.E.; Alizadeh, D.; Starr, R.; Weng, L.; Wagner, J.R.; Naranjo, A.; Ostberg, J.R.; Blanchard, M.S.; Kilpatrick, J.; Simpson, J.; et al. Regression of Glioblastoma after Chimeric Antigen Receptor T-Cell Therapy. N. Engl. J. Med. 2016, 375, 2561-2569. [CrossRef] [PubMed]

53. Parato, K.A.; Senger, D.; Forsyth, P.A.J.; Bell, J.C. Recent progress in the battle between oncolytic viruses and tumours. Nat. Rev. Cancer 2005, 5, 965-976. [CrossRef] [PubMed]

54. Kaufmann, J.K.; Chiocca, E.A. Glioma virus therapies between bench and bedside. Neuro-Oncology 2014, 16, 334-351. [CrossRef] [PubMed]

55. Wollmann, G.; Ozduman, K.; van den Pol, A.N. Oncolytic virus therapy for glioblastoma multiforme: Concepts and candidates. Cancer J. 2012, 18, 69-81. [CrossRef] [PubMed]

56. Aghi, M.; Visted, T.; DePinho, R.A.; Chiocca, E.A. Oncolytic herpes virus with defective ICP6 specifically replicates in quiescent cells with homozygous genetic mutations in p16. Oncogene 2008, 27, 4249-4254. [CrossRef] [PubMed]

57. Alonso, M.M.; García-Moure, M.; Gonzalez-Huarriz, M.; Marigil, M.; Hernandez-Alcoceba, R.; Buñales, M.; Hervás, S.; Gallego, J.; Gomez-Manzano, C.; Fueyo, J.; et al. Abstract CT027: Oncolytic virus DNX-2401 with a short course of temozolomide for glioblastoma at first recurrence: Clinical data and prognostic biomarkers. Cancer Res. 2017, 13, 77. [CrossRef]

58. Tejada, S.; Alonso, M.; Patiño, A.; Fueyo, J.; Gomez-Manzano, C.; Diez-Valle, R. Phase I Trial of DNX-2401 for Diffuse Intrinsic Pontine Glioma Newly Diagnosed in Pediatric Patients. Neurosurgery 2017. [CrossRef] [PubMed]

59. Ji, N.; Weng, D.; Liu, C.; Gu, Z.; Chen, S.; Guo, Y.; Fan, Z.; Wang, X.; Chen, J.; Zhao, J.; et al. Adenovirus-mediated delivery of herpes simplex virus thymidine kinase administration improves outcome of recurrent high-grade glioma. Oncotarget 2016, 7, 4369-4378. [CrossRef] [PubMed] 
60. Mitchell, L.A.; Lopez Espinoza, F.; Mendoza, D.; Kato, Y.; Inagaki, A.; Hiraoka, K.; Kasahara, N.; Gruber, H.E.; Jolly, D.J.; Robbins, J.M. Toca 511 gene transfer and treatment with the prodrug, 5-fluorocytosine, promotes durable antitumor immunity in a mouse glioma model. Neuro-Oncology 2017, 19, 930-939. [CrossRef] [PubMed]

61. Winograd, E.K.; Ciesielski, M.J.; Fenstermaker, R.A. Novel vaccines for glioblastoma: Clinical update and perspective. Immunotherapy 2016, 8, 1293-1308. [CrossRef] [PubMed]

62. Neagu, M.R.; Reardon, D.A. Rindopepimut vaccine and bevacizumab combination therapy: Improving survival rates in relapsed glioblastoma patients? Immunotherapy 2015, 7, 603-606. [CrossRef] [PubMed]

63. Reardon, D.A.; Desjardins, A.; Schuster, J.; Tran, D.D.; Fink, K.L.; Nabors, L.B.; Li, G.; Bota, D.A.; Lukas, R.V.; Ashby, L.S.; et al. ReACT: Long-term survival from a randomized phase II study of rindopepimut (cdx-110) plus bevacizumab in relapsed glioblastoma. Neuro-Oncology 2015, 17, v109.1. [CrossRef]

64. Weller, M.; Butowski, N.; Tran, D.D.; Recht, L.D.; Lim, M.; Hirte, H.; Ashby, L.; Mechtler, L.; Goldlust, S.A.; Iwamoto, F.; et al. Rindopepimut with temozolomide for patients with newly diagnosed, EGFRvIII-expressing glioblastoma (ACT IV): A randomised, double-blind, international phase 3 trial. Lancet Oncol. 2017, 18, 1373-1385. [CrossRef]

(C) 2018 by the authors. Licensee MDPI, Basel, Switzerland. This article is an open access article distributed under the terms and conditions of the Creative Commons Attribution (CC BY) license (http://creativecommons.org/licenses/by/4.0/). 